\title{
THE EFFECTS OF A GAMIFIED HUMAN RESOURCE MANAGEMENT SYSTEM ON JOB SATISFACTION AND ENGAGEMENT
}

\author{
MARIO SILIC \\ University of St. Gallen - Institute of Information Management \\ mario.silic@unisg.ch \\ GiACOMO MARZI \\ Lincoln International Business School - University of Lincoln \\ gmarzi@lincoln.ac.uk \\ Andrea Caputo \\ Lincoln International Business School - University of Lincoln \\ acaputo@lincoln.ac.uk \\ MATTHIJS BAL \\ Lincoln International Business School - University of Lincoln \\ mabal@lincoln.ac.uk
}

Published in Human Resource Management Journal

Full Text (DOI): https://dx.doi.org/10.1111/1748-8583.12272

\begin{abstract}
The pressures associated with the speed of competition, including the digitalization of workspaces, are increasing the need for modern organizations to drive employee satisfaction and engagement. Integrating gamification into the workplace has been identified as a possible strategy to promote employee participation, engagement, and loyalty. Gamification is defined as the application of game design elements in a non-game context, which, in this case, is the workplace. This article presents a 12-month longitudinal study designed to investigate the role of gamification in fostering job satisfaction and engagement. The findings from a sample of 398 employees, including both treatment and control groups from a large multinational company that introduced a gamified human resource management (HRM) system, revealed the effects of certain gamification experiential outcomes related to driving employee satisfaction and engagement at work. Overall, our study highlights the possibilities of employing gamified HRM systems to influence employee attitudes and behavior at work.
\end{abstract}

Keywords: HRM system; gamification; job satisfaction; job engagement; workplace gamification; flow 